\title{
Prototipe Layanan Video on Demand (VoD) Pada Jaringan OpenFlow
}

\author{
Eki Ahmad Zaki Hamidi \\ Program Studi Teknik Elektro \\ UIN Sunan Gunung Djati Bandung \\ ekiahmadzaki@uinsgd.ac.id
}

\author{
Nanang Ismail \\ Program Studi Teknik Elektro \\ UIN Sunan Gunung Djati Bandung \\ nanang.is@uinsgd.ac.id
}

\author{
Rizka Jalaludin \\ Program Studi Teknik Elektro \\ UIN Sunan Gunung Djati Bandung \\ rizkajalaludin32@gmail.com
}

\begin{abstract}
Abstrak - Sistem distribusi Video on Demand (VoD) saat ini umumnya masih menggunakan sistem transmisi konvensional. Perkembangan jaringan yang makin kompleks menuntut manajemen yang semakin handal. Software-Defined Networking (SDN) hadir untuk mengatasi kompleksitas sistem dengan memisahkan control plane dan data plane. Salah satu protokol SDN adalah OpenFlow. Makalah ini membahas tentang simulasi layanan VoD melalui jaringan OpenFlow. Realisasi OpenFlow menggunakan OpenvSwitch. Sistem disimulasikan dengan 1 PC server, 1 PC untuk switch dengan OpenvSwitch, dan 3 PC client. Hasil simulasi menunjukan QoS VoD melalui jaringan OpenFlow sudah memenuhi standar ITU-T G.1010 dengan delay sebesar $3,31 \mathrm{~ms}$, jitter sebesar $0 \mathrm{~ms}$, packet loss sebesar $0 \%$, dan throughput sebesar 2,71 Mbit/s. Penilaian Mean Opinion Score (MOS) juga sudah memenuhi standar ITU-T P.800 dengan nilai 3417,06 dan termasuk kategori baik.
\end{abstract}

Kata Kunci: MOS, OpenFlow, OpenvSwitch, QoS, Software-Defined Networking, Video On Demand.

\section{PENDAHULUAN}

Perkembangan yang sangat pesat pada teknologi berbasis IP mendorong munculnya berbagai inovasi layanan multimedia. Kemajuan ini ditandai dengan berkembangnya berbagai produk teknologi baik dari sisi media maupun perangkat. Salah satu layanan multimedia yang memanfaatkan perkembangan teknologi berbasis IP adalah Video on Demand (VoD) [1][2].

VoD adalah istilah untuk layanan penyajian video yang bisa diakses online secara streaming melalui jaringan berbasis IP [1][3]. Layanan ini didasarkan pada permintaan end user [4]. VoD saat ini menjadi pesaing dalam bisnis televisi berlangganan [1][2]. VoD memiliki berbagai kelebihan, salah satunya adalah memberikan kontrol terhadap para penggunanya. Melalui konsep ini pengguna akan memiliki kebebasan penuh untuk memilih apa yang ingin ia lihat. User dapat melakukan pause, fastforward, rewind, dan lain-lain). Semuanya berjalan secara interaktif dan menggunakan tombol serta perintah yang sederhana [1][4][5].

Beberapa contoh video server yaitu Youtube, Metacafe, Dailymotion, dan sebagainya. Bahkan layanan IPTV yang dipromosikan Indihome Telkom juga memperkenakan layanan VoD. Adanya video server, memudahkan user untuk saling berbagi (share) video baik secara online maupun non-online.

VoD mempunyai beberapa kelemahan, diantaranya adalah bahwa aplikasi VoD membutuhkan alokasi bandwidth yang lebih besar daripada aplikasi streaming suara. Pada VoD, ketika bandwidth multimedia lebih besar daripada kecepatan transmisi rata-rata yang diterima maka akan terjadi kongesti/tubrukan paket data sehingga menyebabkan beberapa paket hilang [5]. Menurut ITU-T G.1010, aplikasi video streaming membutuhkan nilai $<1 \%$ PLR (Packet Loss Ratio) [6].

Untuk mendukung jaringan internet masa depan, maka diperlukan suatu "fully managed virtualization network framework" untuk menyediakan koneksi dari beberapa komponen yang ada dengan dilengkapi platform layanan virtual yang memenuhi semua persyaratan dari layanan tersebut. Virtualisasi jaringan akan berusaha menjalankan beberapa jaringan dalam infrastruktur yang sama (shared), tanpa adanya penurunan performansi atau kestabilan jaringan karena interferensi antar jaringan. Untuk memberikan inovasi yang cepat dan menyembunyikan kompleksitas dalam desain jaringan, maka diperlukan suatu paradigma baru, yaitu Software-Defined Networking (SDN) [7].

Software-Defined Networking (SDN) adalah satu jaringan komputer yang sangat fleksibel karena ia dikonfigurasi dan dikendalikan melalui software terpusat. SDN ini di kembangkan oleh Stanford University yang mengeluarkan teknologi OpenFlow. Dengan pengaplikasian OpenFlow, pengguna dapat menganalisis gambaran kebutuhan pertumbuhan jaringan, yang dapat diamati langsung hanya melalui sebuah aplikasi. SDN memungkinkan administrator sistem untuk mempercepat koneksi penyediaan jaringan [7] [8].

Artikel ini membahas tentang simulasi VoD melalui jaringan OpenFlow untuk melihat sejauh mana dukungan jaringan OpenFlow dalam mendukung transmisi Video on Demand (VoD).

\section{LANDASAN TEORI}

\section{A. Video on Demand}

Video on demand adalah layanan berdasarkan permintaan end-user, yang memungkinkan user untuk memilih dan 
melihat konten video yang ingin ditonton, dimana end-user dapat mengontrol konten video yang ditonton (misal: dapat melakukan pause, fastforward, rewind, dan lain-lain) [4]. Namun pada sistem yang menggunakan metode streaming, hal ini akan membebani server dan memerlukan pemakaian bandwidth yang lebih besar.

Konsep dasar dari $V o D$ adalah menyimpan program/konten dan kemudian dikirimkan ke penonton ketika diminta oleh penonton tersebut. Penyimpanannya berupa server tersentralisasi yang menggunakan perangkat untuk mengirimkan pemrograman secara simultan ke ratusan penonton, atau dapat pula menggunakan penyimpanan lain yang terdistribusi ke seluruh jaringan. Untuk membatasinya, perangkat penyimpanan individu untuk tiap penonton dapat diletakkan di masing-masing set top box [2][4].

VoD memiliki beberapa tipe layanan, antara lain: True Video on demand (VoD), Near Video on demand (NVoD), Subscription Video on demand (SVoD), Free Video on Demand (FVoD), Everything on Demand (EoD), Personal Video Recorders (PVRs), Network Personal Video Recorders (NPVRs), dan Pay Per View (PPV) [2].

\section{B. Internet Protocol (IP)}

Internet Protocol atau protokol internet didesain untuk interkoneksi sistem komunikasi komputer pada jaringan paket switched. Internet Protocol menyediakan skema pengalamatan yang seragam sehingga komputer pada satu jaringan dapat berkomunikasi dengan komputer pada jaringan yang lain [9][10].

\section{Software-Defined Networking (SDN)}

SDN adalah sebuah pendekatan baru dalam mendesain, membangun, dan mengelola jaringan komputer. Pada dasarnya SDN memisahkan data dan fungsi kontrol perangkat jaringan seperti router, packet switch, dan switch LAN. Secara umum dalam perangkat networking terdapat dua bagian, yaitu control plane dan data plane. Dengan demikian SDN dapat didefinisikan sebagai Aplication Programing Interface (API) [8][11]. Control plane adalah bagian yang berfungsi untuk mengatur logika pada perangkat networking seperti routing table, pemetaan jaringan dan sebagainya. Data plane adalah bagian yang berfungsi untuk meneruskan paket-paket yang masuk ke suatu port pada perangkat networking menuju port keluar dengan berkonsultasi kepada control plane [10][11][12].

Gambar 1 menggambarkan pandangan logis dari arsitektur SDN. Jaringan intelijen (logis) dipusatkan di perangkat lunak berbasis pengendali SDN, yang mempertahankan pandangan global dari jaringan. Akibatnya, jaringan muncul ke aplikasi dan kebijakan mesin yang tunggal (satu). Dengan SDN, perusahaan dan operator mendapatkan kontrol vendor-independen di seluruh jaringan dari titik logis tunggal, yang sangat menyederhanakan desain jaringan dan operasi. SDN juga sangat menyederhanakan perangkat jaringan sendiri, karena mereka tidak lagi perlu memahami dan memproses ribuan standar protokol tetapi hanya menerima instruksi dari pengendali SDN [12].

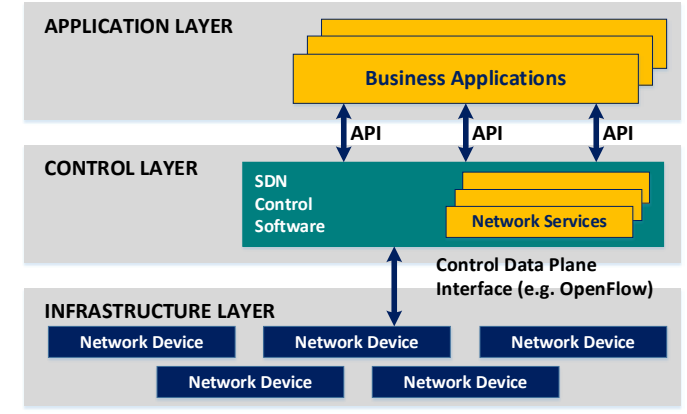

Gambar 1. Arsitektur Software-Defined Networking [12].

\section{OpenFlow}

Untuk mengubah konsep SDN ke implementasi praktis OpenFlow, dua persyaratan yang harus dipenuhi. Pertama, harus ada arsitektur logis umum di semua switch, router, dan perangkat jaringan lainnya yang akan dikelola oleh pengontrol SDN. Arsitektur logis ini dapat diimplementasikan dengan cara yang berbeda pada peralatan vendor yang berbeda dan di berbagai jenis perangkat jaringan, asalkan controller SDN melihat fungsi saklar seragam. Kedua, standar protokol aman diperlukan antara controller SDN dan perangkat jaringan. Kedua persyaratan ini ditangani oleh OpenFlow, yang merupakan sebuah protokol antara SDN controller dan perangkat jaringan, serta spesifikasi struktur logis dari fungsi switch jaringan [11][12][13][14][15].

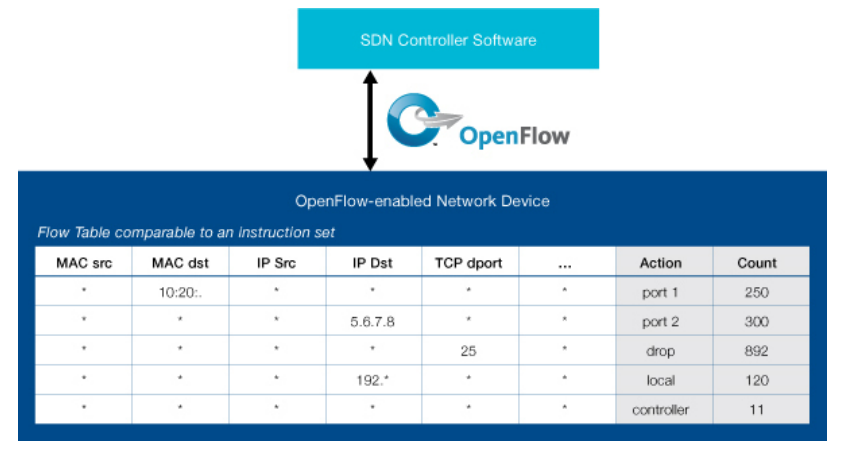

Gambar 2. Contoh kumpulan perintah OpenFlow [15].

Berikut ini adalah format Flow yang digunakan:

\begin{tabular}{|c|c|c|c|c|c|c|c|c|c|c|c|}
\hline Ingress & MAC & MAC & Ether & VLAN & P- & IP & IP & IP & IP & TCP/UDP & TCP/UDP \\
Port & DA & SA & type & ID & Bits & Src & Dst & Protoco & DSCP & src port & dst port \\
\hline
\end{tabular}

\section{Gambar 3. Format Flow [15].}

\section{E. Switch OpenFlow}

Switch OpenFlow atau yang biasa disebut OpenvSwitch merupakan implementasi switch OpenFlow yang dapat digunakan baik sebagai saklar virtual murni dalam lingkungan virtual dan sebagai saklar software tujuan umum yang menghubungkan node secara fisik yang terpisah. Switch OpenFlow adalah referensi yang awalnya dikembangkan oleh Stanford University dan kemudian 
dilanjutkan Open Networking Foundation (ONF). OpenFlow Switch meliputi komponen dan fungsi dasar yang dibutuhkan oleh perangkat networking untuk mendukung OpenFlow [16][17][18].

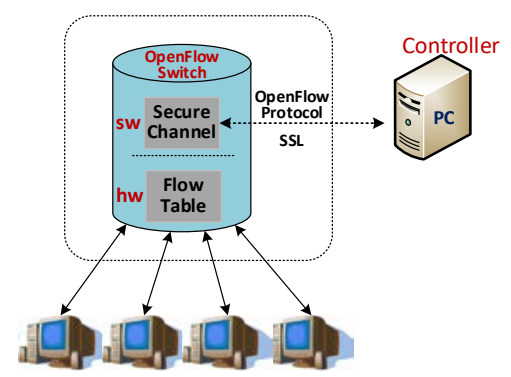

Gambar 4. Arsitektur OpenvSwitch [17].

Gambar 4 menunjukkan arsitektur Switch OpenFlow yang mendukung OpenFlow (yang selanjutnya disebut OpenFlow switch) sesuai referensi OpenFlow Switch Specification versi 1.3.0. OpenFlow switch berkomunikasi dengan controller melalui protokol OpenFlow. OpenFlow switch terdiri dari tiga bagian yaitu [17]:

a) Flow Table

OpenFlow Switch terdiri dari satu atau lebih flow table yang berfungsi untuk memproses paket yang datang.

b) Secure Channel

Secure channel merupakan sebuah interface yang menghubungkan OpenFlow switch dan controller.

c) OpenFlow Protocol

OpenFlow protocol menyediakan sebuah cara yang bersifat terbuka dan standar untuk bisa berkomunikasi dengan OpenFlow switch.

\section{METODOLOGI PENELITIAN}

Metodologi yang digunakan dalam penelitian ini mengacu pada tahapan pada Gambar 5.

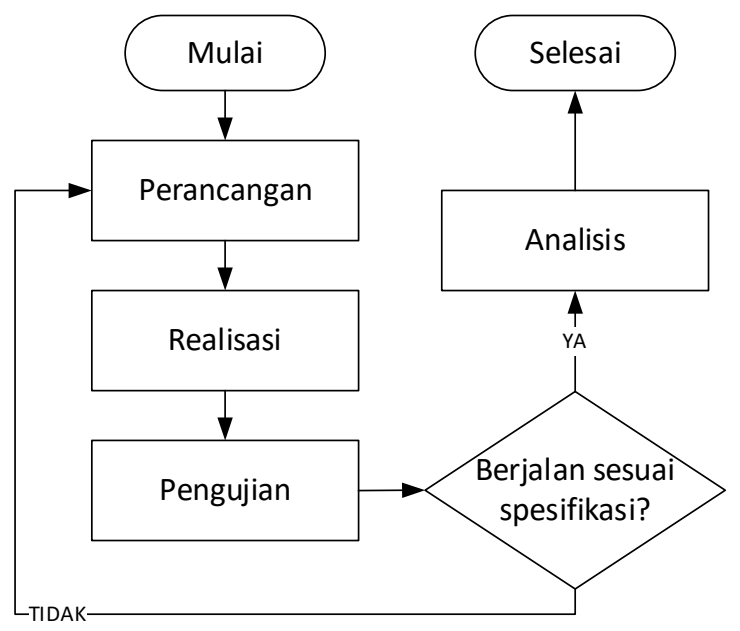

Gambar 5. Diagram Alir Penelitian.
A. Perancangan Sistem

Pada tahapan ini akan dilakukan pemodelan topologi jaringan. Selain itu pada tahapan ini akan dirancang antar muka halaman web VoD.

\section{B. Realisasi Sistem}

Rancangan yang sudah dibuat selanjutnya direalisasikan untuk mendapatkan prototipe VoD pada jaringan OpenFlow. Dimana sistem akan melibatkan satu PC server, Switch, dan 3 client. Spesifikasi perangkat keras yang digunakan adalah sebagai berikut:

a) Satu unit Komputer dengan operating system Windows 8 (trial) berfungsi sebagai server dengan spesifikasi sebagai berikut:

- Processor: Intel (R) Pentium (R) Dual CPU E2200 @ $2.20 \mathrm{GHz}$

- RAM: $1.00 \mathrm{~GB}$

b) Tiga unit Komputer dengan operating system Windows 8 (trial) berfungsi sebagai client dengan spesifikasi sebagai berikut:

- Processor: Intel (R) Pentium (R) Dual CPU E2200 @ $2.20 \mathrm{GHz}$

- RAM: $1.00 \mathrm{~GB}$

c) Satu unit komputer dengan operating system Linux Debian berfungsi menjalankan switch OpenFlow (OpenVswitch) dengan spesifikasi sebagai berikut:

- Processor: Intel Core2Duo

- RAM: $1.00 \mathrm{~GB}$

d) Kabel LAN sebagai media transmisi data dari server menuju client.

C. Pengujian dan Analisis Sistem Skenario pengujian terdiri dari beberapa tahap, yaitu:

- Pengujian konektivitas dengan menguji flow antara server - client

- Pengujian QoS yang mencakup parameter: delay, jitter, packet loss, dan throughput,

- Pengujian Mean Opinion Score (MOS) untuk menguji kualitas VoD menurut user.

Masing-masing data hasil uji akan dianalisis ketercapaiannya.

\section{HASIL DAN PEMBAHASAN}

A. Perancangan Arsitektur Sistem Video on Demand

Pada perancangan skema sistem VoD ini, sistem dibuat agar user dapat dengan mudah mengaksesnya. Dengan perangkat yang mudah untuk diimplementasikan. Sistem Video on Demand (VoD) dirancang berbasis Web (Web Base). Topologi jaringan yang dibuat mengacu pada Gambar 6. 


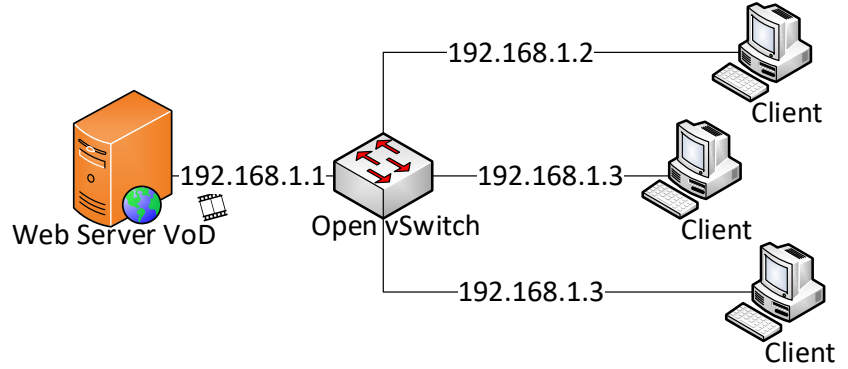

Gambar 6. Topologi Jaringan.

Web server menggunakan XAMPP versi 1.8.1. XAMPP dipilih karena merupakan opensource dan mampu mendukung banyak sistem operasi.

Streaming VoD server dibuat sebagai penyimpan file-file video yang akan di-streaming-kan kepada client/user. Filefile video akan disimpan dalam folder Htdocs. VoD ini berisikan empat kategori, yaitu:

- Hiburan, berisikan video-video hiburan

- Islami, berisikan video pembacaan Surah Al Quran, ceramah keagamaan dan pembacaan shalawat,

- Sepak Bola, berisikan video cuplikan-cuplikan dokumentasi pemain sepak bola dunia, dan

- Video Clip, berisikan video klip musik.

Jaringan OpenFlow menggunakan software OpenVSwitch (Switch OpenFlow), yang bertindak sebagai switch penghubung antara client ke server dengan media transmisi kaber RJ45. Streaming video dilakukan secara multicast maupun unicast.

\section{B. Perancangan Web Server VoD}

Web server berfungsi menerima permintaan HTTP dari client melalui web browser dan akan mengirimkan hasilnya dalam bentuk halaman-halaman web yang berbentuk dokumen HTML. Web server VoD yang menggunakan software XAMPP 1.8.1 ini merupakan perangkat untuk server yang berfungsi menyimpan file-file video dan mengirimkan streaming video ke client. Server ini akan menerima permintaan streaming dari client, lalu server akan mendistribusikan data dari database ke halaman web VoD dan di-streaming-kan ke client yang meminta layanan VoD tersebut. Arsitektur sistem VoD server diperlihatkan pada Gambar 7.

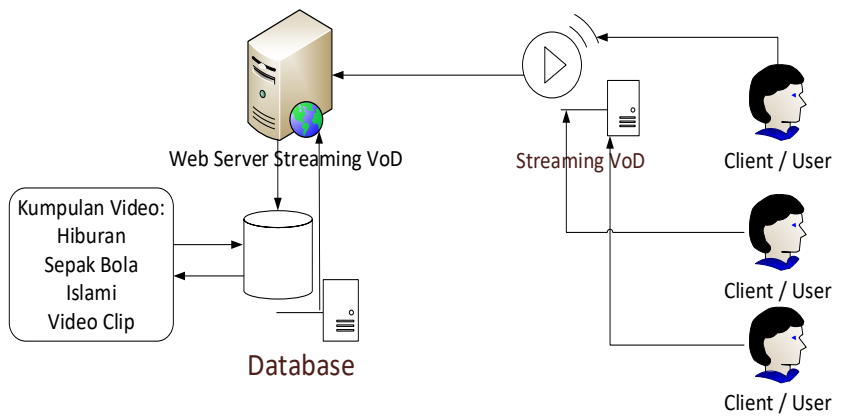

Pada penelitian ini digunakan personal computer yang digunakan sebagai server yang meyimpan dan menstreaming-kan video-video yang ada di server terhadap client. Gambar 8 menunjukkan cara client melakukan request dan menonton video.

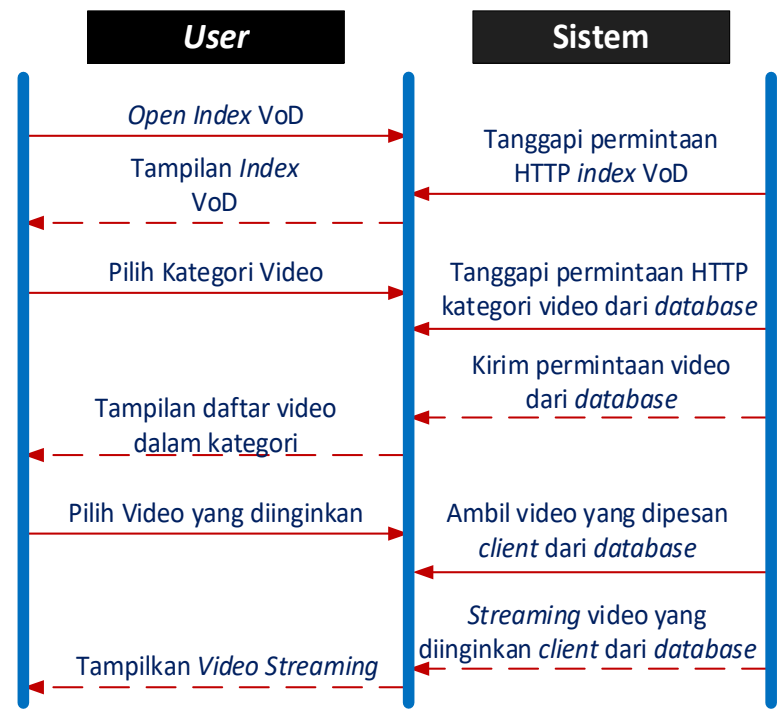

Gambar 8. Sequence diagram untuk request VoD.

C. Perancangan Tampilan Homepage VoD

Homepage VoD terdiri dari 2 halaman utama, yaitu:

i. Layar Home/Menu Utama

Halaman Home merupakan halaman awal yang tampil saat user mengakses website VOD. Tampilan layar home dapat dilihat pada Gambar 9.

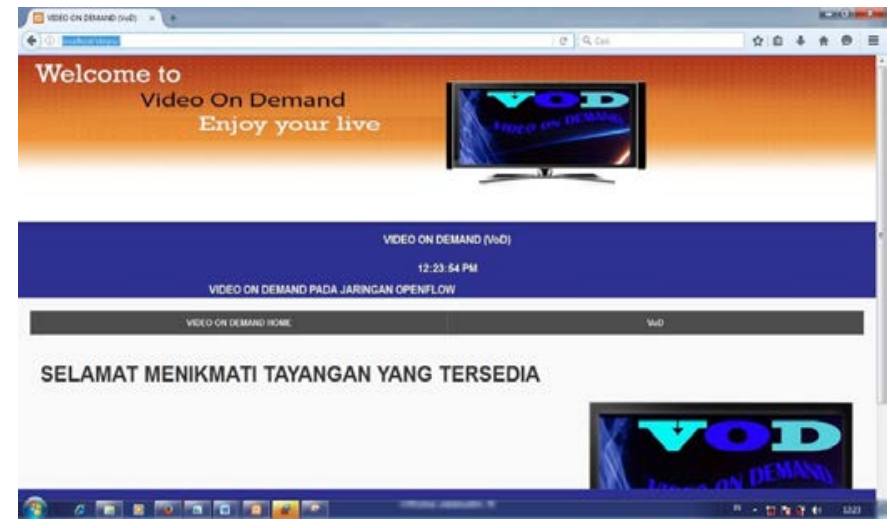

Gambar 9. Halaman Menu Utama VoD.

ii. Layar $\operatorname{VoD}$

Halaman Video on Demand (VoD) berisikan empat kategori VOD yang tersedia. Layar VoD dapat dilihat pada Gambar 10.

Gambar 7. Arsitektur Sistem VoD Server. 

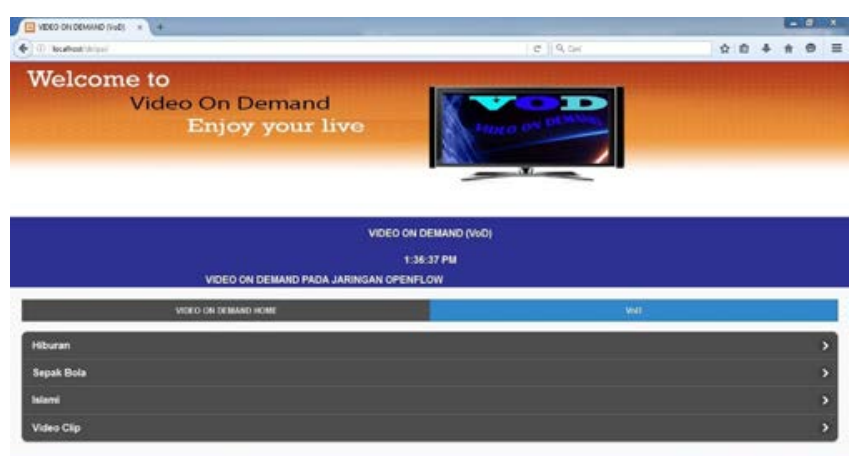

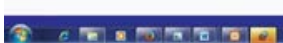

Gambar 10. Tampilan Kategori VoD.

D. Pengujian dan Analisis

i. Analisis Flow

Flow yang digunakan adalah sebagai berikut: root@debian: \# ovs-ofctl add-flow ovs0 arp,action=normal

root@debian: \# ovs-ofctl add-flow ovs0 "priority=65535,in_port=1,action=output:2,3,4” root@debian: \# ovs-ofctl add-flow ovs0 "priority=65535,in_port=2,action=output:1" root@debian: \# ovs-ofctl add-flow ovs0 "priority=65535,in_port=3,action=output:1" root@debian: \# ovs-ofctl add-flow ovs0 "priority=65535,in_port=4,action=output:1"

Flow tersebut menunjukan Video On Demand (VoD) telah berhasil diimplementasikan pada jaringan OpenFlow. Server dapat mem-broadcast video kepada ketiga client.

ii. Analisis Dump Flow

Dump flow digunakan untuk melihat paket-paket yang digunakan dalam OpenFlow. Analisis hasil dump flow dapat dikutahui pada Gambar 11.

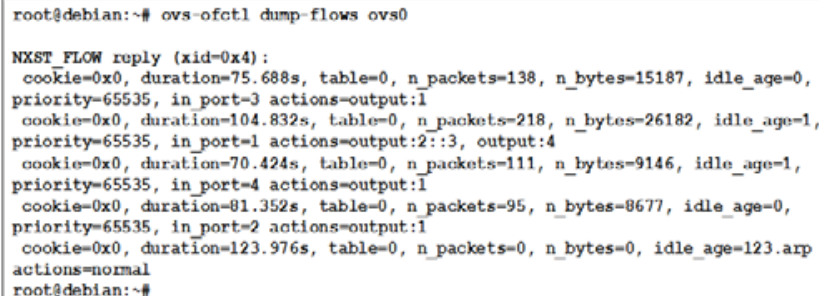

Gambar 11. Dump Flow

Flow dari port 3 ke port 1 atau dari client (IP 192.168.1.2) ke server memiliki durasi pemakaian flow sebesar 75,688 s, banyaknya paket flow adalah 138 paket. Ukuran paketnya sebesar 15187 byte. Lama flow tidak dipakai bernilai 0 karena flow tidak pernah berada pada keadaan off, dengan priority sebesar 65535.

Flow dari port 1 ke port 2, 3, 4 atau koneksi dari server ke semua client memiliki durasi flow sebesar 104,832 s, banyak paket flow sebesar 218 paket, dengan ukuran paket sebesar 26182 byte. Lama flow tidak digunakan hanya 1 kali.

Flow dari port 4 ke port 1 atau dari client dengan IP 192.168.1.3 ke server, memiliki durasi flow sebesar 70,424 s, dan banyak paket flow adalah 111 paket dengan ukuran paketnya sebesar 9146 byte. Lama flow yang tidak dipakai 0 karena flow tidak pernah berada dalam posisi off.

Flow dari port 2 ke port 1 atau dari client dengan IP 192.168.1.4 ke server, memiliki durasi flow sebesar $81,352 \mathrm{~s}$, dan banyak paket flow yang digunakan sebesar 95 paket, dengan ukuran paketnya sebesar 8677 byte. Lama flow yang tidak dipakai 0 karena flow tidak pernah berada dalam keadaan off.

Ketika semua port tidak melakukan interkoneksi dari server ke client, memiliki durasi sebanyak 123,87 s. Lama flow tidak dipakai adalah 123 kali. Pada penelitian ini priority-nya adalah 65535 yang merupakan nilai priority terbesar di dalam OpenvSwitch. Ketika priority paling besar maka posisi flow-nya paling tinggi. Namun bukan berarti flow tersebut di-forward paling pertama namun fungsi memasukan sebuah priority bertujuan supaya administrator bisa mengetahui posisi flow itu berada.

\section{iii. Quality of Service}

- Delay

Hasil pengukuran menunjukan bahwa delay tidak melebihi standar yang ditetapkan oleh ITU-T G.1010 tentang delay yang disarankan yaitu kurang dari 150 ms.

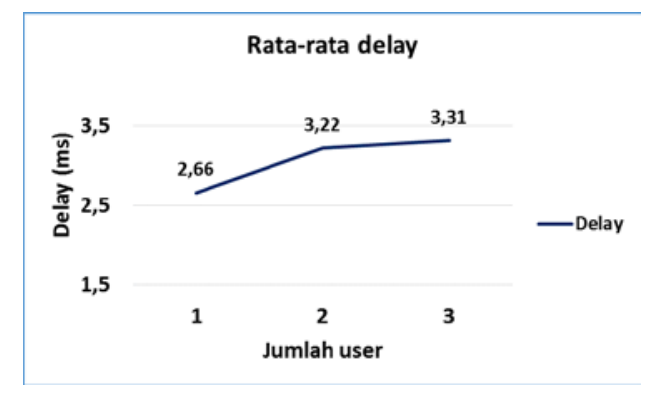

Gambar 12. Rata-Rata Delay Transmisi VoD Pada Jaingan OpenFlow

Dari Gambar 12, dapat dilihat bahwa peningkatan delay pada streraming VoD server dipengaruhi oleh adanya penambahan user. Hal ini disebabkan oleh semakin meningkatnya antrian sehingga paket yang dikirim semakin lama. Delay untuk 3 user sebesar 3,3112 ms. Delay yang ada masih sesuai dengan standar ITU-T G.1010 yaitu kurang dari 150 ms.

- Jitter

Hasil pengukuran menunjukkan bahwa tidak ada perubahan nilai jitter (konstan). Tidak adanya perubahan nilai jitter disebabkan karena jarak antara server dan client pada ujicoba hanya sejauh $1 \mathrm{~m}$. 


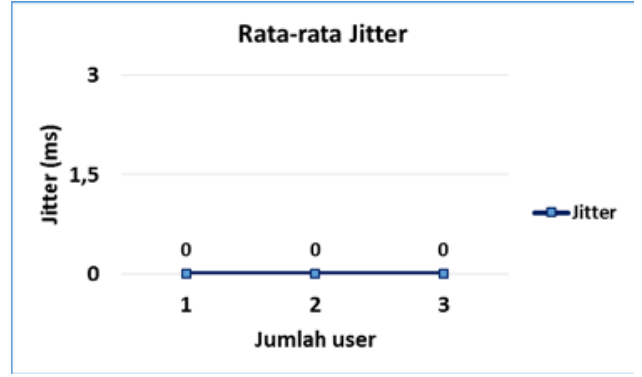

Gambar 13. Rata-rata Jitter Transmisi VoD Pada Jaingan OpenFlow.

Dapat dilihat bahwa nilai jitter adalah konstan 0 ms. Dengan demikian jitter untuk jaringan yang dibangun sesuai dengan standar ITU - T G.1010 yaitu dengan nilai jitter 0 ms (sangat bagus).

- Packet Loss

Penyebab utama packet loss adalah hilangnya paket akibat antrian. Pada pengamatan yang telah dilakukan, perubahan jumlah user mempengaruhi paket data yang hilang. Namun karena simulasi hanya menggunakan 3 client dengan jarak ke server hanya 1 meter, tidak ada packet loss pada transmisi VoD yang dilakukan. Gambar. 14 menunjukan rerata packet loss pada uji coba VoD yang dilakukan.

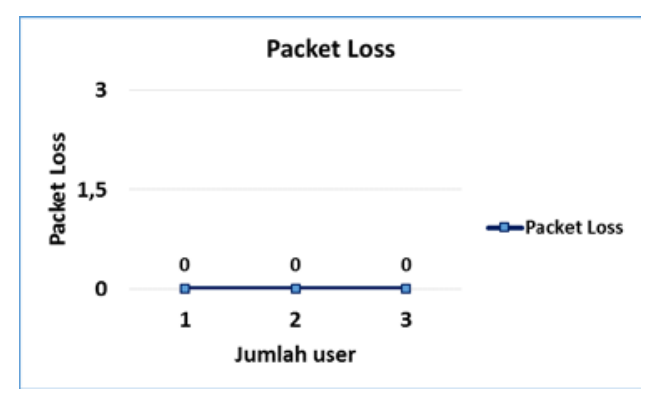

Gambar 14. Packet Loss pada transmisi VoD pada Jaringan OpenFlow.

- Throughput

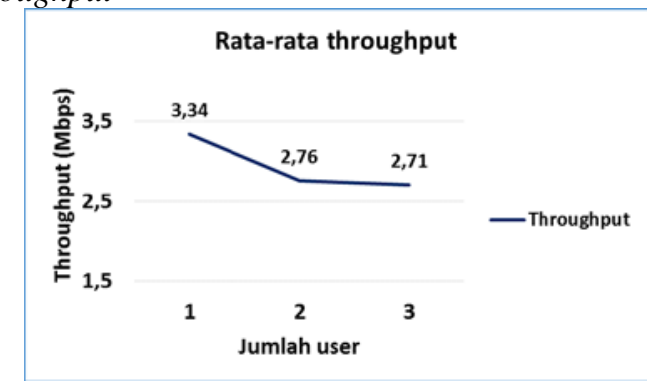

Gambar 15. Grafik Throughput VoD Pada Jaingan OpenFlow.

Hasil analisis menunjukkan bahwa rata-rata throughput mengalami penurunan nilai pada saat terjadi penambahan user. Nilai throughput terkecil terjadi ketika server diakses oleh 3 user. Nilai throughput akan semakin berkurang seiring bertambahnya user yang mengakses layanan VoD. Throughput bernilai 3,42 Mbit/s ketika diakses 1 user, ketika di akses oleh 3 user bernilai 2,71 Mbit/s.

\section{iv. Mean Opinion Score (MOS)}

Perhitungan nilai MOS (Mean Opinion Score) dilakukan berdasarkan pendekatan matematis dengan E-Model yang distandarkan kepada ITU-T G.107. Nilai akhir estimasi E-Model disebut dengan R faktor menggunakan persamaan (1) di bawah ini [3][19]:

$R=94,2-I d-I e f$

$R=$ Faktor kualitas transmisi.

$I d=$ Merupakan faktor penurunan kualitas yang disebabkan oleh pengaruh delay

Ief = Merupakan faktor penurunan kualitas yang disebabkan oleh packet loss yang terjadi.

Nilai Id ditentukan dari persamaan (4) sebagai berikut [3][20]:

$I d=0,024 d+0.11(d-177,3) H(d-177,3)$

Dengan nilai $d$ (delay) sebesar 3,31 ms, dan $\mathrm{H}$ adalah fungsi tangga, maka:

$I d=0,024(3,3112)+0,11 .(3,31-177,3)(1)(3,31-177,3)$

$I d=0,0794+0,11 \cdot(-173,99) \cdot 1 \cdot(-1773,99)$

$I d=0,0794+(-19,14)(-173,99)$

$I d=0,0794+(-3.329,93)$

$I d=-3.329,86$

Nilai Ief dapat ditentukan dari persamaan (3) sebagai berikut [3] [19]:

Ief $=7+30 \ln (1+15 e)$

dimana $e$ adalah Packet loss yang didapat pada penelitian, bernilai 0, maka:

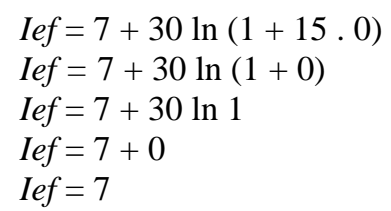

Setelah nilai Id dan Ief diketahui, maka nilai $\mathrm{R}$ dapat diperoleh dengan memasukannya ke persamaan (1).

$$
\begin{aligned}
& R=94,2-(-3.329,86)-7 \\
& R=3424,06-7 \\
& R=3417,06
\end{aligned}
$$

Berdasarkan ketentuan ITU-T P.800 bahwa [3] [20]: 
- $\quad R<0 ;$ maka MOS = 1

- $R>100$; maka MOS = 4,5

- $0<R<100$ maka MOS $=1+0,035 R+7 \times 10^{-6} R(R$ 60)(100-R))

Dengan nilai R sebesar 3417, 06, maka didapat nilai MOS sebesar 4,5. Berdasarkan rekomendasi ITU T P.800.2 nilai 4,5 termasuk pada kategori baik.

Hasil dari kuisioner yang diambil dari 10 orang responden yang telah mencoba sistem, didapatkan hasil untuk tampilan web sebanyak $60 \%$ responden menyatakan bahwa tampilan sistem bagus, 70\% menyatakan sistem sangat mudah untuk digunakan, dan $50 \%$ menyatakan kualitas gambar streaming yang dihasilkan bagus.

\section{KESIMPULAN}

Berdasarkan perancangan prototipe layanan Video on Demand (VoD) pada jaringan OpenFlow, maka dapat disimpulkan bahwa konsep teknologi OpenFlow dapat diterapkan dengan baik pada aplikasi Video on Demand (VoD). Dan berdasarkan hasil pengujian, parameter QoS yang diamati sudah memenuhi standar yang ditetapkan ITU - T, dengan hasil delay sebesar 3,31 ms, jitter sebesar 0,0 ms, packet loss sebesar $0 \%$, dan throughput sebesar 2,71 Mbit/s. Untuk hasil perhitungan matematis, nilai MOS sebesar 3417,06, termasuk pada kategori baik.

\section{REFERENSI}

[1] Lestariningati, S.I., Zarman, W., \& Perdana, D. (2011). Perancangan dan Implementasi Video On Demand Pada Jaringan Lokal. Majalah Ilmiah UNIKOM, Vol. 9, No. 1, pp. 11-20.

[2] Simpson, W. \& Greenfield, H. (2012). IPTV and Internet Video Expanding the Reach of Television. USA: National Association of Broadcasters, CRC Press.

[3] W, HP, Susilawati, H. \& Noviandono, R.K. (2013). Analisis Performansi VoIP (Voice over Internet Protocol) Pada Jaringan WiMax (Worldwide Interoperability for Microwave Access) di Wilayah Jakarta. Jakarta: Universitas Jendral Sudirman.

[4] Muryanti, S.D.P. \& Affandi, A. (2015). Rancang Bangun Sistem Keamanan Konten Video On Demand (VOD) Pada Internet Protocol Television (IPTV) Menggunakan Video Encryption Algorithm (VEA). Surabaya: Jurusan Teknik Elektro, ITS.

[5] Marpaung, K.W., W, A.P \& Ambarwati, R. (2011). Desain Video on Demand (VOD) Menggunakan High Speed Downlink Packet Access (HSDPA) di Wilayah Urban Kota Malang. Malang: Unibraw.

[6] ITU-T. (2011). ITU-T Recommendation G.1010: End-
User Multimedia QoS Categories. ITU-T.

[7] Risdianto, A.C. (2012). Implementation and Analysis of Control and Forwarding Plane for Software Defined Network. Bandung: ITB.

[8] Faruqi, N.A., Nurwadi, L., Ismail, N. \& Maryanto, D. (2017). Simulasi Kinerja Berbagai Topologi Jaringan Berbasis Software-Defined Network (SDN). Seminar Nasional Teknik Elektro UIN Sunan Gunung Djati Bandung (SENTER 2017). Bandung.

[9] Sardju, A.P. (2012). Implementasi IPTV (Internet Protocol Television) Berbasis Web Pada Jaringan Wireless. Makassar: Universitas Hasanudin.

[10] Ismail, N. (2006). Sistem Keamanan pada IPTV (Internet Protocol Television). Bandung: Bidang Khusus Teknologi Informasi Sekolah Teknik Elektro dan Informatika Institut Teknologi Bandung.

[11] McKeown, N. \& De Boer, M. (2008). Performance Analysis of OpenFlow Hardware. USA: Standford University.

[12] Stallings, W. (2013). Software-defined Networks and Openflow. The Internet Protocol Journal, Vol. 16, No. 1, pp. 2-14.

[13] Limoncelli, T.A. (2012). Openflow: a radical new idea in networking. Queue, Vol. 10, No. 6, pp. 40.

[14] Hamidi, E.A.Z. (2015) The Simulation of VLAN Using OpenFlow at Laboratory of Electrical Engineering. The 2015 International Conference on Electrical, Telecommunication and Computer Engineering. Medan.

[15] Open Networking Fundation. (2012). Software-defined Networking: The New Norm for Networks. ONF White Paper, Vol. 2, pp. 2-6.

[16] Wijaksa, D.S., Mardiati, R., Ismail, N. \& Juhana, T. (2016). TestBed Open vSwitch Raspberry Pi Pada Skala Kecil. Seminar Nasional Teknik Elektro UIN Sunan Gunung Djati Bandung (SENTER 2016). Bandung.

[17] Hakim, A. (2014). Implementasi Dan Analisis Kinerja Switch OpenFlow dan Switch Konvensional Pada Jaringan Komputer. Bogor: Institut Pertanian Bogor.

[18] Effendi, M.R., Hamidi, E.A.Z \& Saepulloh, A. (2017). Implementasi GRE Tunneling Menggunakan Open vSwitch Pada Jaringan Kampus. TELKA - Jurnal Telekomunikasi, Elektronika, Komputasi dan Kontrol, Vol. 3, No. 2, pp. 103-111.

[19] ITU-T. (2014). Recommendation ITU-T G.107: The Emodel: a Computational Model for Use in Transmission Planning. ITU-T.

[20] ITU-T. (2013). Recommendation ITU-T P.800.2: Mean opinion score interpretation and reporting. ITU-T. 